\title{
O caracol-gigante-africano Achatina fulica (Bowdich, 1822): análise do conteúdo em livros didáticos de ciências e biologia indicados pelo programa nacional do livro didático (PNLD) 2017 e 2018
}

Laura Rocha Guerino laurargue@ig.com.br 0000-0003-4705-1019 UNIBr Faculdade de São Vicente, São Vicente, São Paulo, Brasil.

Aparecido Guerino profguerinoguerino@gmail.com 0000-0002-0288-3076

Colégio Centurion, Praia Grande, São Paulo, Brasil.

\section{RESUMO}

Verificou-se a presença de conteúdos sobre o caracol-gigante-africano Achatina fulica nas coleções de Ciências e Biologia indicados pelo PNLD 2017/2018, quanto a presença de imagens e informações referentes à transmissão de doenças, e alertas sobre manejo e controle da população dessa espécie exótica invasora. Os resultados revelaram a ausência de qualquer menção sobre o molusco em 50 \% das coleções de Ciências e em 30 \% das coleções de Biologia, omissões/incorreções em conceitos e imagens, e algumas legendas equivocadas nos conteúdos encontrados. Concluiu-se que há necessidade de melhores critérios na elaboração dessas coleções ao tratar de temas de interesse à saúde pública e ao meio ambiente, pois informações corretas contribuem na construção do conhecimento e na formação de atitudes que minimizam o risco de se contrair doenças além de evitar a frequente confusão entre o Achatina fulica e o molusco nativo Megalobulimus sp ameaçado de extinção.

PALAVRAS-CHAVE: Molusco africano. Molusco invasor. Saúde pública. Meio ambiente. 


\section{INTRODUÇÃO}

A educação em saúde é de extrema importância para os jovens em idade escolar. Ela deve ser inserida no seu dia a dia e tratada de forma a orientar o jovem acerca dos riscos de se adquirir uma enfermidade e as formas adequadas de profilaxia para si e seus familiares. Sendo as parasitoses um dos muitos problemas de saúde pública no Brasil - país com grande diversidade cultural e poderes aquisitivos desiguais -, faz-se necessário que esses jovens sejam instruídos no ambiente escolar e, para isso, o livro didático é uma ferramenta adequada.

O PNLD/2018 de Biologia preconiza que os livros didáticos devem trazer os conhecimentos científicos de forma didática para o contexto escolar, conectando a linguagem científica com a do cotidiano do aluno para promover a melhor aprendizagem possível.

Segundo Lajolo (1996), o livro didático é um instrumento importante para o ensino formal e, apesar de não ser o único material que possa ser utilizado em sala de aula, é uma ferramenta decisiva para a qualidade do aprendizado advindo do ambiente escolar; é um dos principais recursos utilizados pelos professores no seu trabalho diário de preparação de aulas e, para os alunos, é uma das únicas fontes de pesquisa e estudo (SANTOS et al., 2007), tornando-se um importante aliado para seu aprendizado, em detrimento, muitas vezes, de outras fontes de informação disponíveis.

Embora os Parâmetros Curriculares Nacionais recomendem a utilização, além do livro didático, de materiais diversificados como jornais, revistas, vídeos, etc. (BRASIL, 1998), o professor pode fazer uso em sala de aula também de outros materiais como videoaulas, experimentos, textos e entrevistas disponibilizados na internet, visando ampliar a abrangência dos conteúdos e fazer com que o aluno se sinta inserido no mundo à sua volta. Todavia, a realidade da maioria das escolas mostra que o livro didático tem sido praticamente o único instrumento de apoio do professor e fonte de estudo e pesquisa para os estudantes (FRISON et al., 2009).

Ainda que o professor deva sempre pesquisar bibliografias variadas e consultar outros meios que the possibilitem consolidar os conhecimentos (VERCEZE; SILVINO, 2008), no Brasil os livros didáticos se tornaram uma importante e eficaz forma de divulgar informações para a sociedade sobre as diversas doenças que acometem a população e respectivas medidas profiláticas, e, para que isso ocorra de forma correta e proveitosa, Frison et al. (2009) destacam que é fundamental que os professores estejam preparados e munidos de livros e materiais didáticos adequados com conteúdo correto e coerente.

No quesito educação em saúde, parasitoses como a meningite (ou meningoencefalite) eosinofílica ${ }^{1}$, cujo agente etiológico pode ser hospedado e transmitido pelo caracol-gigante-africano Achatina fulica, pouco tem merecido a atenção dos autores desses livros.

A meningoencefalite eosinofílica - doença grave com vários casos já reportados no Brasil - pode ser causada também pelo nematoide Angiostrongylus cantonensis (Chen, 1935), que se dispersou pelo mundo a partir do leste Asiático

\footnotetext{
${ }^{1}$ Meningite eosinofílica: Inflamação nas meninges causada por vermes.
}

Página | 271 
em ratos (hospedeiros definitivos) e em moluscos-gigantes-africanos $A$. fulica - um dos hospedeiros intermediários -, especialmente durante a Segunda Guerra Mundial (KLIKS; PALUMBO, 1992).

No Brasil, os casos humanos de meningoencefalite eosinofílica causada pelo nematoide $A$. cantonensis já ocorreram nos estados de São Paulo, Rio Grande do Sul, Rio de Janeiro, Paraná, Espírito Santo e Pernambuco, sendo que moluscos e/ou roedores infectados com o parasito já foram reportados nos estados do Amazonas, Bahia, Ceará, Paraná, Pará, Rio de Janeiro, Rio Grande do Sul, São Paulo e Santa Catarina (MORASSUTTI et al, 2014) tornando essa parasitose uma infecção de crescente importância em saúde pública.

O homem torna-se hospedeiro acidental dessa parasitose ao ingerir o molusco infectado cru ou malcozido ou ainda alimentos e água contaminados com larvas L3 - formas infectantes para o hospedeiro definitivo (WEN, 1977) - presentes no tecido fibromuscular e no muco ou, ainda, quando em contato com os hospedeiros paratênicos ${ }^{2}$. Uma vez ingeridas, essas larvas migram para o sistema nervoso central (SNC) e se alojam nas meninges, onde são a causa mais comum de meningite eosinofílica (MENEZES, 2014), uma condição séria que pode levar à morte ou a danos permanentes ao cérebro.

Geralmente essa doença é autolimitada pois os parasitos não conseguem se reproduzir no ser humano e morrem naturalmente. No entanto alguns pacientes podem desenvolver as formas graves e o índice de mortes é de 3\%. O atraso no diagnóstico é um dos fatores que contribuem para o agravamento desse quadro, uma vez que os aspectos clínicos são comuns a muitas outras infecções o que torna os exames clínicos incapazes de distingui-la das meningites virais, da tuberculose e até mesmo da gripe comum (MORASSUTTI et al, 2014) - a maioria dos casos de meningite eosinofílica em Taiwan foi reportada em crianças expostas ao $A$. fulica (TSAl et al., 2001).

O A. fulica (Figura 1) é um gastrópode pulmonado terrestre conhecido como caracol-gigante-africano. Adultos dessa espécie atingem tamanho avantajado, podendo ser encontrados indivíduos com conchas de até $20 \mathrm{~cm}$ de altura e $10 \mathrm{~cm}$ a $12 \mathrm{~cm}$ de largura, chegando a pesar até $500 \mathrm{~g}$. Está na lista das 100 principais espécies invasoras do mundo (LOWE et al., 2004).

São hermafroditas de fecundação cruzada adquirindo a maturidade sexual em cerca de 100 a 120 dias. Cada indivíduo pode realizar de 3 a 5 posturas anuais, cada uma com 200 ovos em média, que normalmente são enterrados.

Quanto à alimentação, são generalistas - devoram todas as partes de plantas nativas, ornamentais, selvagens e de cultura -, e canibais pois também devoram ovos e caramujos jovens da mesma espécie (PAIVA, 2004), além de papel, jornal, entulho, fezes e lixo em geral.

Presente em 25 Estados e no Distrito Federal englobando diferentes ecossistemas em todo o Brasil (TELES et al., 1997; VASCONCELOS; PILE, 2001; OLIVEIRA et al., 2013), o A. fulica é extremamente resistente a longos períodos de

\footnotetext{
${ }^{2}$ Hospedeiro paratênico: hospedeiro intermediário no qual o parasito não sofre desenvolvimento ou reprodução, mas permanece viável até atingir novo hospedeiro definitivo.
}

Página | 272 
seca e a variações climáticas. Entra em estado de estivação ${ }^{3}$ quando as condições ambientais se tornam desfavoráveis - o caracol seleciona um local protegido, se retrai no interior da concha e a fecha com o epifragma ${ }^{4}$ (FISCHER; COLLEY, 2005).

Essa característica lhes confere alta adaptabilidade ao ambiente e os indivíduos não encontram dificuldades para crescer e se multiplicar intensamente causando prejuízos ambientais e econômicos. Segundo Castro (2006), atingiu o status de "Espécie Exótica Invasora" 5 que mais causa danos ao meio ambiente e à agricultura no Brasil.

Em várias regiões do Brasil o $A$. fulica é confundido com os moluscos do gênero Megalobulimus (Figura 2), espécie da nossa fauna, devido ao tamanho semelhante, porém este coloca apenas dois ovos em cada ciclo reprodutivo (THIENGO, 2007), o que lhe confere uma extrema fragilidade quando comparado ao molusco-gigante-africano que pode colocar até 442 ovos em uma única postura (FISCHER; COSTA, 2010).

Figura 1- Caracol-gigante-africano Achatina fulica, em terreno baldio, Praia Grande/SP.

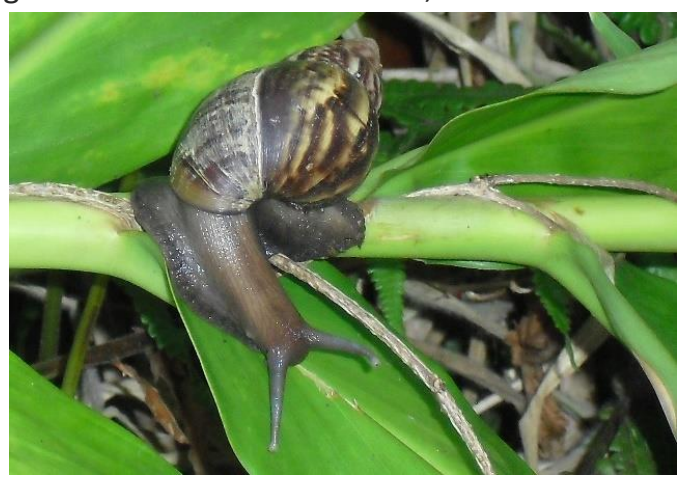

(Fonte: foto autoral)

Figura 2 - Caracol Megalobulimus paranaguensis no parque estadual Xixová-Japui, São Vicente/SP.

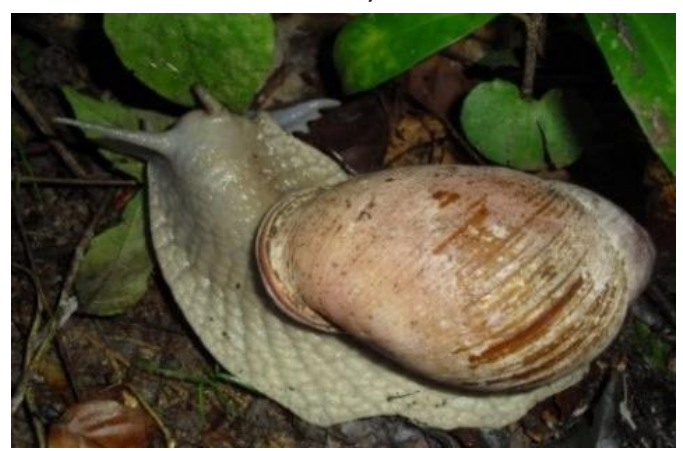

(Fonte: foto autoral).

\footnotetext{
${ }^{3}$ Estivação: estado de torpor aeróbico, que envolve mudanças comportamentais, fisiológicas e bioquímicas e que permitem aos moluscos pulmonados resistir a condições desfavoráveis de umidade, temperatura e disponibilidade de alimento.

${ }^{4}$ Epifragma: Lâmina delgada e mucosa, de natureza calcária segregada por gastrópodes terrestres e que, secando ao ar, exerce a função de obturador transitório da concha, durante o período de estivação.

${ }^{5}$ Espécie exótica invasora: espécie que se encontra fora de sua área de distribuição natural e que prolifera sem controle passando a representar ameaça para espécies nativas e para o equilíbrio dos ecossistemas. Pode representar risco até às pessoas.
}

Página | 273 
Este estudo teve como proposta analisar o conteúdo sobre o molusco $A$. fulica presente nos livros didáticos de Ciências e Biologia indicados pelos PNLD 2017 e 2018 respectivamente.

\section{MATERIAIS E MÉTODOS}

Analisamos os livros didáticos de Ciências para o Ensino Fundamental II aprovados pelo Plano Nacional do Livro Didático de 2017 e de Biologia para o Ensino Médio aprovados pelo Plano Nacional do Livro Didático de 2018, quanto aos conteúdos referentes ao caracol-gigante-africano $A$. fulica.

Das treze coleções aprovadas de Ciências para o Ensino Fundamental II, doze foram analisadas e uma foi excluída devido à sua indisponibilidade nas escolas da região e à dificuldade encontrada em consegui-la junto à editora (Tabela 1). Para o Ensino Médio foram analisadas todas as coleções de Biologia (Tabela 2).

A análise foi realizada de acordo com uma ficha organizada em forma de perguntas com respostas do tipo Sim (S) ou Não (N) (Tabela 3) elaboradas visando detectar a presença de informações que possibilitem ao aluno compreender as causas e as consequências da invasão do território nacional pelo A. fulica e diferenciá-lo do molusco nativo do gênero Megalobulimus. Cada volume que continha algum conteúdo sobre o molusco recebeu um número (1 a 16). Os livros de 1 a 8 são referentes às coleções de Ciências e os de 9 a 16, às coleções de Biologia (Tabelas 1 e 2).

Com relação aos nomes populares dos gastrópodes não há um senso comum entre diversos autores de livros didáticos quando se trata dos conceitos "caracol $X$ caramujo", assim optamos por analisar de acordo com Ruppert et al. (2005) que define caramujos como aquáticos e caracóis e lesmas como terrestres.

Tabela 1. Coleções de Ciências indicadas pelo PNLD 2017 para o Ensino Fundamental II.

\begin{tabular}{|c|c|c|c|c|}
\hline $\begin{array}{l}\text { № da } \\
\text { coleção }\end{array}$ & $\begin{array}{c}\text { Edição/ } \\
\text { Ano }\end{array}$ & Título/ Código & $\begin{array}{l}\text { Livro/ } \\
\text { Ano } \\
\text { escolar }\end{array}$ & Editora \\
\hline \multirow{2}{*}{01} & \multirow{2}{*}{ 2a $/ 2015$} & Tempo de Ciências & $1 / 70$ & \multirow{2}{*}{ Brasil } \\
\hline & & 0149P17032 & $2 / 80$ & \\
\hline 02 & 1a/2015 & $\begin{array}{c}\text { Ciências } \\
\text { 0121P17032 }\end{array}$ & $3 / 70$ & Quinteto \\
\hline 03 & 4a $/ 2014$ & $\begin{array}{c}\text { Projeto Araribá Ciências } \\
\text { 0032P17032 }\end{array}$ & 4/7은 & Moderna \\
\hline \multirow{2}{*}{04} & \multirow{2}{*}{ 4a $/ 2015$} & \multirow{2}{*}{$\begin{array}{c}\text { Companhia das Ciências } \\
\text { 0071P17032 }\end{array}$} & $5 / 60$ & \multirow{2}{*}{ Saraiva } \\
\hline & & & 6/7음 & \\
\hline 05 & 1a/2015 & $\begin{array}{c}\text { Investigar e Conhecer } \\
\text { Ciências da natureza } \\
\text { 0011P17032 }\end{array}$ & 7/7은 & Saraiva \\
\hline 06 & 2a/2015 & $\begin{array}{c}\text { Projeto Teláris Ciências } \\
0022 \mathrm{P} 17032\end{array}$ & $8 / 60$ & Ática \\
\hline
\end{tabular}




\begin{tabular}{|c|c|c|c|c|}
\hline 07 & 2a $/ 2015$ & $\begin{array}{c}\text { Projeto APOEMA - CIÊNCIAS } \\
\text { 0057P17032 }\end{array}$ & $*$ & Brasil \\
\hline 08 & 2a & $\begin{array}{c}\text { Ciências - Novo Pensar } \\
\text { 0064P17032 }\end{array}$ & $*$ & FTD \\
\hline 09 & 5a/2015 & $\begin{array}{c}\text { Ciências Naturais } \\
\text { Aprendendo com o cotidiano } \\
\text { 0021P17032 }\end{array}$ & $*$ & Moderna \\
\hline 10 & 4이린 & $\begin{array}{c}\text { Para viver juntos } \\
\text { Ciências da natureza } \\
\text { 0083P17032 }\end{array}$ & $*$ & SM \\
\hline 11 & 3이/2015 & $\begin{array}{c}\text { Universos } \\
\text { Ciências da natureza } \\
\text { 0084P17032 } \\
\end{array}$ & $*$ & SM \\
\hline 12 & 6a/2015 & $\begin{array}{c}\text { Ciências } \\
\text { 0108P17032 }\end{array}$ & $*$ & Ática \\
\hline 13 & 4a /2015 & $\begin{array}{c}\text { Jornadas.cie - Ciências } \\
\text { 0105P17032 }\end{array}$ & (1) & Saraiva \\
\hline
\end{tabular}

* Não menciona o molusco Achatina fulica em nenhum volume.

(1) Indisponível.

(Fonte: Guia de livros didáticos: PNLD 2017- Ciências).

Tabela 2. Coleções de Biologia indicadas pelo PNLD 2018 para o Ensino Médio.

\begin{tabular}{|c|c|c|c|c|c|}
\hline $\begin{array}{l}\text { № da } \\
\text { coleção }\end{array}$ & $\begin{array}{l}\text { Edição/ } \\
\text { Ano }\end{array}$ & Título/ Código & \multicolumn{2}{|c|}{$\begin{array}{c}\text { Livro/ } \\
\text { Ano } \\
\text { escolar }\end{array}$} & Editora \\
\hline \multirow{2}{*}{01} & \multirow{2}{*}{$3^{a} / 2017$} & \multirow{2}{*}{$\begin{array}{c}\text { Biologia Hoje } \\
0022 \mathrm{P} 18113 \\
\end{array}$} & 9 & 20 & \multirow{2}{*}{ Ática } \\
\hline & & & 10 & 3응 & \\
\hline 02 & $1^{a} / 2016$ & $\begin{array}{c}\text { Integralis - Biologia: Novas } \\
\text { Bases 0058P18113 }\end{array}$ & 11 & 2 & IBEP \\
\hline 03 & $3^{a} / 2016$ & $\begin{array}{l}\text { Ser protagonista - Biologia } \\
\text { 0072P18113 }\end{array}$ & 12 & 2 & $\mathrm{SM}$ \\
\hline 04 & $3^{a} / 2017$ & $\begin{array}{c}\text { Bio } \\
\text { 0109P18113 }\end{array}$ & 13 & 1 & Saraiva \\
\hline 05 & $1 \mathrm{a} / 2016$ & $\begin{array}{c}\text { \#contato Biologia } \\
\text { 0158P17113 } \\
\end{array}$ & 14 & 2 & Quinteto \\
\hline 06 & $1 \% / 2016$ & $\begin{array}{c}\text { Biologia Unidade e Diversidade } \\
\text { 0182P18113 }\end{array}$ & 15 & 2 & FTD \\
\hline 07 & $2^{a} / 2016$ & $\begin{array}{l}\text { Conexões com a Biologia } \\
\text { 0199P18113 }\end{array}$ & 16 & 3 & Moderna \\
\hline 08 & $12^{\mathrm{a}} / 2017$ & $\begin{array}{c}\text { Biologia } \\
\text { 0107P18113 }\end{array}$ & & & Saraiva \\
\hline 09 & $1 \% / 2016$ & $\begin{array}{c}\text { Biologia Moderna } \\
0196 \mathrm{P} 18113\end{array}$ & & & Moderna \\
\hline 10 & $3^{a} / 2016$ & $\begin{array}{c}\text { Biologia } \\
\text { 0208P18113 }\end{array}$ & & & AJS \\
\hline
\end{tabular}

* Não menciona o molusco Achatina fulica em nenhum volume.

(Fonte: Guia de livros didáticos: PNLD 2018- Biologia). 
Tabela 3. Ficha de análise de conteúdo com respostas tipo "SIM" (S) ou "NÃO" (N).

\begin{tabular}{|c|c|c|c|c|c|c|c|c|c|c|c|c|c|c|c|c|}
\hline Coleção & \multicolumn{8}{|c|}{ Ciências } & \multicolumn{8}{|c|}{ Biologia } \\
\hline Livro & 1 & 2 & 3 & 4 & 5 & 6 & 7 & 8 & 9 & 10 & 11 & 12 & 13 & 14 & 15 & 16 \\
\hline \multicolumn{17}{|l|}{ Nomes: } \\
\hline Científico & $\mathrm{S}$ & $\mathrm{S}$ & \multicolumn{2}{|c|}{\begin{tabular}{l|l}
$\mathrm{N}$ & $\mathrm{S}^{2}$ \\
\end{tabular}} & $\mathrm{~S}$ & $S$ & $\mathrm{~S}$ & $\mathrm{~S}$ & $\mathrm{~S}$ & $S$ & $S$ & $S$ & $S$ & $S$ & $S$ & $S$ \\
\hline Populares & $\mathrm{S}$ & $\mathrm{S}$ & & $\mathrm{N}$ & \multicolumn{2}{|c|}{\begin{tabular}{l|l}
$S$ & $S^{4}$ \\
\end{tabular}} & \multicolumn{2}{|c|}{\begin{tabular}{l|l}
$S$ & $S^{4}$ \\
\end{tabular}} & $S^{4}$ & $\mathrm{~S}^{4}$ & $\mathrm{~S}^{4}$ & $\mathrm{~S}^{4}$ & $S^{4}$ & $\mathrm{~S}^{9}$ & $\mathrm{~N}$ & $\mathrm{~S}^{4}$ \\
\hline \multicolumn{17}{|l|}{ Imagens: } \\
\hline Possui & $S$ & $S$ & $S$ & $\mathrm{~S}$ & $S$ & $\mathrm{~N}$ & $S$ & $\mathrm{~N}$ & $S$ & $\mathrm{~S}$ & $S$ & $\mathrm{~N}$ & $S$ & $S$ & $S$ & $\mathrm{~S}$ \\
\hline Corretas & $\mathrm{N}$ & $\mathrm{S}$ & $S$ & $\mathrm{~S}$ & $\mathrm{~S}$ & - & $\mathrm{S}$ & - & $\mathrm{S}$ & $S^{7}$ & $S$ & - & $S$ & $S^{7}$ & $S$ & $\mathrm{~N}$ \\
\hline Nítidas & $\mathrm{S}$ & $\mathrm{S}$ & $S$ & $\mathrm{~S}$ & $\mathrm{~S}$ & - & $\mathrm{S}$ & - & $\mathrm{S}$ & $\mathrm{S}$ & $S$ & - & $S$ & $S$ & $\mathrm{~S}$ & $S$ \\
\hline Histórico & $\mathrm{N}$ & $\mathrm{S}$ & $\mathrm{S}$ & $\mathrm{N}$ & $\mathrm{N}$ & $\mathrm{S}$ & $\mathrm{S}$ & $\mathrm{S}$ & $\mathrm{S}$ & $\mathrm{S}$ & $\mathrm{N}$ & $\mathrm{S}$ & $\mathrm{S}$ & $\mathrm{S}$ & $\mathrm{N}$ & $\mathrm{N}$ \\
\hline Voracidade & $\mathrm{N}$ & $\mathrm{S}$ & $S$ & $\mathrm{~N}$ & $\mathrm{~N}$ & $S$ & $\mathrm{~S}$ & $\mathrm{~N}$ & $\mathrm{~N}$ & $\mathrm{~N}$ & $\mathrm{~N}$ & $\mathrm{~S}$ & $S$ & $\mathrm{~N}$ & $\mathrm{~N}$ & $\mathrm{~N}$ \\
\hline Reprodução & $\mathrm{N}$ & $\mathrm{N}$ & $\mathrm{N}$ & $\mathrm{N}$ & $\mathrm{S}$ & $\mathrm{N}$ & $\mathrm{S}$ & $\mathrm{N}$ & $S^{5}$ & $\mathrm{~N}$ & $\mathrm{~S}$ & $\mathrm{~N}$ & $\mathrm{~N}$ & $\mathrm{~S}^{8}$ & $\mathrm{~N}$ & $\mathrm{~N}$ \\
\hline $\begin{array}{l}\text { Transmissão } \\
\text { de parasitos }\end{array}$ & $\mathrm{N}$ & $\mathrm{N}$ & $\mathrm{N}$ & $\mathrm{N}$ & $\mathrm{N}^{3}$ & $\mathrm{~N}$ & $\mathrm{~S}$ & $\mathrm{~N}$ & $S^{6}$ & $\mathrm{~N}$ & $S$ & $S$ & $\mathrm{~S}^{10}$ & $S^{11}$ & $\mathrm{~N}$ & $\mathrm{~N}$ \\
\hline $\begin{array}{c}\text { Medidas de } \\
\text { controle }\end{array}$ & $\mathrm{N}$ & $\mathrm{N}$ & $S$ & $\mathrm{~N}$ & $\mathrm{~N}$ & $\mathrm{~N}$ & $\mathrm{~S}$ & $\mathrm{~N}$ & $\mathrm{~N}$ & $\mathrm{~N}$ & $S$ & $\mathrm{~N}$ & $\mathrm{~N}$ & $\mathrm{~N}$ & $\mathrm{~N}$ & $\mathrm{~N}$ \\
\hline
\end{tabular}

(Fonte: Tabela elaborada pelos autores).

(1) Usa o termo "caramujo-africano" em substituição ao termo "caracol-giganteafricano".

(2) Usa o termo "caramujo Achatina fulica" em substituição ao termo "caracol Achatina fulica".

(3) Informa apenas que pode transmitir doenças.

(4) Usa o termo "caramujo-gigante-africano" em substituição ao termo "caracolgigante-africano".

(5) Informa apenas que se "reproduz rapidamente".

(6) Informa somente que pode ser hospedeiro intermediário de vermes causadores de doenças em seres humanos e animais domésticos.

(7) A imagem difere em coloração dos exemplares encontrados no Brasil.

(8) Informa apenas que tem alta taxa de reprodução.

(9) Usa o termo "Caracol-africano" em substituição ao termo comum "caracolgigante-africano".

(10) Apenas informa que "atua como transmissora de duas zoonoses e outras parasitoses de interesse veterinário".

(11) Informa apenas que é hospedeiros de vermes que parasitam os seres humanos.

\section{RESULTADOS}

\section{Presença de conteúdo sobre o $A$. fulica}

Das doze coleções de Ciências analisadas apenas seis (50\%) apresentam algum conteúdo sobre o molusco em pelo menos um volume; quanto às coleções de Biologia, dez foram analisadas e sete $(70 \%)$ apresentaram algum conteúdo sobre o tema. 


\section{Nomes científico e populares}

O nome científico "Achatina fulica" não foi citado apenas no livro 3 e o livro 7 não cita nenhum nome popular para o molusco. Os demais livros apresentam nomes populares variados que estão indicados na tabela 3 .

\section{Imagens}

Os livros 6, 8 e 12 não apresentaram imagens do $A$. fulica enquanto que os demais livros apresentaram uma ou mais imagens.

Todas as imagens apresentadas são nítidas e coloridas embora nem todas sejam as corretas:

- no livro 10 a imagem do caracol tem uma coloração corpórea muito clara com concha amarelada e com lábio espessado (Figura 3 A) e no livro 14 a imagem também tem concha amarelada mas a coloração corpórea é acinzentada (figura 3 B), o que não são características comuns aos $A$. fulica encontrados no Brasil (Figura 1);

- nos livros 1 e 16 as imagens apresentadas são de exemplares do molusco nativo Megalobulimus sp (Figura 4), porém as respectivas legendas referem-se ao $A$. fulica.

- A imagem que acompanha o texto no livro 3, apesar de ser do A. fulica, apresenta alguns ovos que, pelo tamanho, não pertencem a essa espécie (Figura 5), sendo muito parecidos com os ovos do Megalobulimus sp. (Figura 6 à esquerda).

Figura 3: A - Caracol com coloração corpórea clara e concha amarelada com lábio espessado; B - Caracol com concha amarelada e coloração corpórea acinzentada.

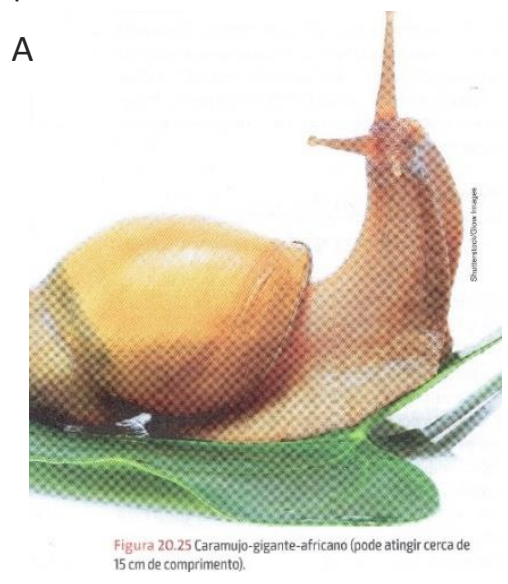

A

(Fontes: A - Livro 09 - Biologia Hoje, 3을 Ano, p. 280; B - livro 14 - \#contato Biologia, 2ㅇ Ano, p. 163).

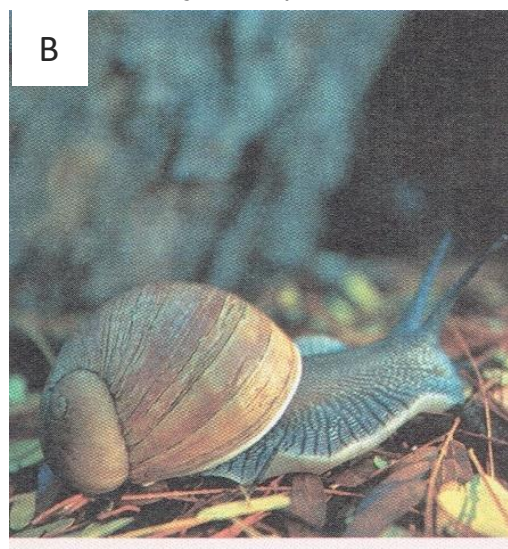

Caracol da espécie Achatina fulica. 
Figura 4 - Caracol Megalobulimus sp com legenda referente ao Achatina fulica.

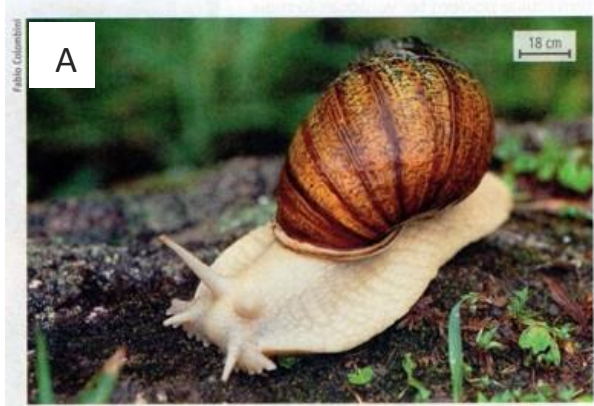

Introdurido no Brasil na década de 1980, o carcol gigante afficano (Achatina fulica) Ec considerado uma praga no país. A espécie foi trarida como opchio ao consumo

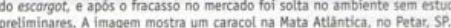

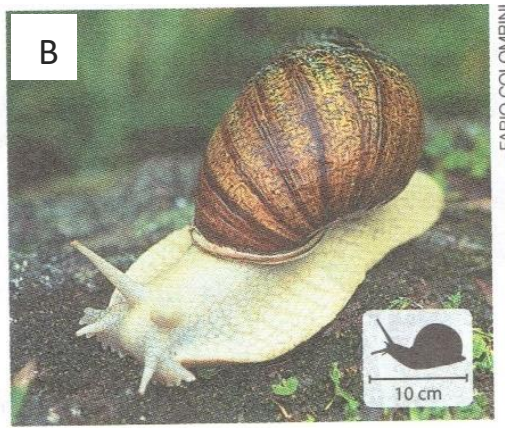

Caramujo-gigante-africano (Achatina fulica), espécie invasora muito comum no Brasil. É considerado praga agrícola, problema ambiental e de saúde, por se reproduzir muito rápido e ser hospedeiro intermediário de algumas doenças.

(Fontes: A - Livro 01 - Tempo de Ciências, 7o Ano, p. 138; B - livro 16 - Conexões com a Biologia, 3읏 Ano, p. 231).

Figura 5 - Caracol com ovos em livro de Ciências.

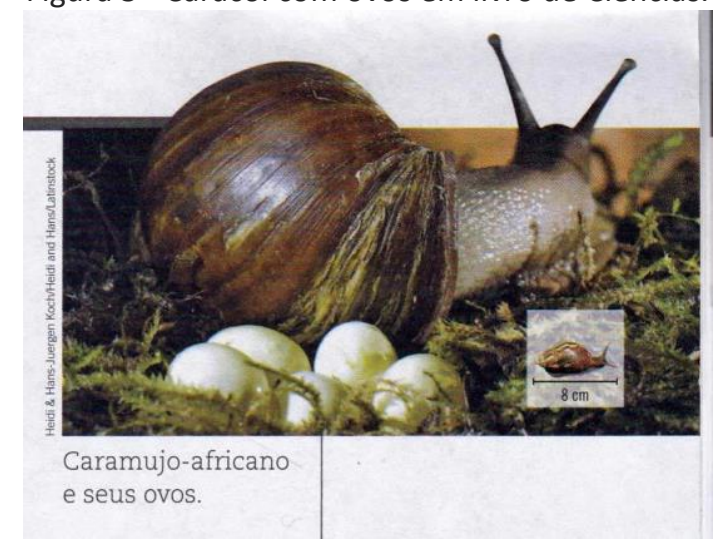

(Fonte: Livro 3 - Ciências, 7o Ano, p. 145).

Figura 6 - Ovos - à esquerda de Megalobulimus paranaguensis e à direita de Achatina fulica.

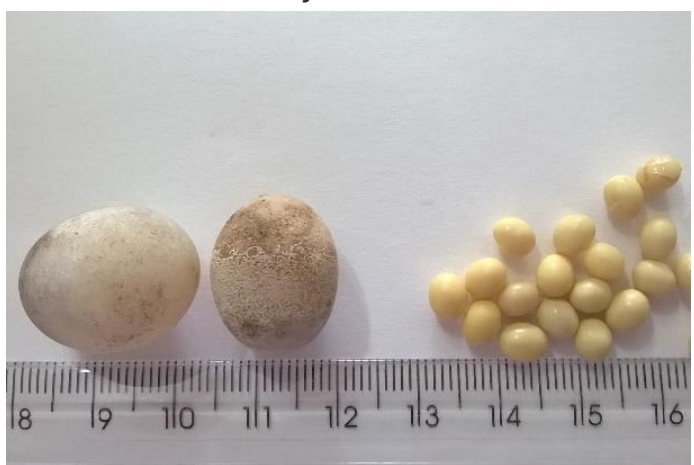

(Fonte: Foto autoral). 
O livro 7 traz uma página inteira dedicada ao A. fulica sob o título "O caramujogigante-africano e o desequilíbrio ecológico" com texto bastante claro, preciso e conciso. Nos livros 1, 4, 5, 11, 15 e 16 não há nenhuma referência.

Nos demais volumes o tema é abordado de diferentes formas:

- no livro 2 uma atividade ressalta o papel do molusco como praga agrícola;

- o livro 3 traz um pequeno texto para debate em sala de aula;

- o livro 6 limita-se apenas a informar que o "A. fulica foi introduzido no Brasil para ser criado comercialmente como alternativa ao escargot (Helix aspersa)";

- o livro 8 apresenta um texto com poucas informações na sessão "Os invasores" do capítulo sobre "Relações entre os seres vivos", dando ênfase ao fato de ser exótico.

- o livro 9 traz um texto pequeno no quadro "Biologia e ambiente" do capítulo 11 "Moluscos e Anelídeos" limitando-se a informar que a criação de $A$. fulica fracassou e que escaparam dos locais de criação espalhando-se pelo ambiente;

- o livro 10 apenas cita sua introdução no Brasil e o fracasso de sua comercialização e a consequente invasão ao ambiente, com o histórico muito reduzido;

- o livro 12 traz um texto bem elucidativo sob o título "Moluscos exóticos: boa ou má notícia", sendo o único a informar que a importação das matrizes foi clandestina por não haver registro oficial da autorização de importação;

- o livro 13 limita-se a informar que foi importado para consumo em substituição ao escargot, porém sem aceitação foram soltos no ambiente;

- no livro 14 o A. fulica é citado apenas em um exercício da página de atividades do capítulo 8 que engloba platelmintos, nematódeos e moluscos, onde o histórico é bastante reduzido dando ênfase ao descarte dos mesmos, pelos produtores, em rios, terrenos baldios e junto com resíduos sólidos.

\section{Voracidade}

A voracidade somente foi citada nos livros 2, 3, 6, 7, 12 e 13 e todos classificam - A. fulica como praga agrícola por ser generalista causador de prejuízos ambientais e econômicos; O livro 13 é o único a citar que pode levar à perda da biodiversidade local devido ao seu potencial competitivo.

\section{Taxa de reprodução}

A alta taxa de reprodução foi reportada vagamente somente em cinco livros: o no 5 apenas informa que "a população tem crescimento maior, em número, do 
que as espécies nativas"; o № 7 expõe que "os indivíduos são hermafroditas $e$ produzem milhares de ovos por ano"; o no 9 se limita a informar que se "reproduz rapidamente"; o livro 11 informa que se reproduzem "intensamente (cada exemplar pode colocar 200 ovos por postura e se reproduzir mais de uma vez por ano)"; o livro 14 informa que "tem alta taxa de reprodução e adaptação, competindo com as espécies nativas, reduzindo suas populações".

\section{Transmissão de parasitos}

O livro 3 informa tão-somente que "pode transmitir doenças". Nos livros 7, 9, $11,12,13$ e 14 a transmissão de parasitos é mencionada de forma superficial (tabela 3). O livro 11 é o único a citar que o $A$. fulica pode ser portador do Angiostrongylus abstrusus causador de pneumonia em gatos além de citar a meningoencefalite eosinofílica em humanos e descrever parcialmente o ciclo do $A$. cantonensis.

\section{Medidas de controle}

Somente os livros 3 e 7, ambos destinados ao 7으 Ano EF, e o livro 11 destinado ao 2 ano do Ensino Médio apresentaram as medidas de controle para a contenção da invasão do ambiente pelo $A$. fulica. O livro 13 cita que o combate de modo indiscriminado à essa espécie tem colocado em risco as populações de moluscos nativos como o Megalobulimus sp.

\section{DISCUSSÃO}

Não há nenhuma referência ao $A$. fulica em metade das coleções de Ciências e em $30 \%$ das coleções de Biologia. Esses dados nos levam a crer que os alunos das escolas que adotaram essas coleções poderão deixar de adquirir conhecimentos importantes para lidar com essa espécie exótica, presente em todas as regiões brasileiras e que, possivelmente, encontrarão tanto em seu caminho quanto em áreas de sua escola. Pereira et al. (2012), em pesquisa realizada no município da Barra do Piraí/RJ-Brasil com alunos do ensino fundamental, relatam que:

\footnotetext{
De acordo com os estudantes, os caramujos estão dentro da escola, nos quintais de casa, na praça, e são usados até em brincadeiras: "Os meninos aqui da escola que brincam ali, pegam os caramujos e ficam jogando nas meninas". (PEREIRA et al., 2012, p. 280).
}

Esse comportamento pode ser decorrente da falta ou da falha na informação que chega até o aluno e uma das implicações pode ser a sua contaminação pelo parasito e o possível desenvolvimento da meningite eosinofílica.

Todo ser vivo catalogado cientificamente recebe um nome científico exclusivo de forma que sua espécie seja reconhecida universalmente, enquanto os nomes populares são diversos dependendo da cultura regional. Segundo Murta et al. 
(2014) as nomenclaturas populares presentes nos livros didáticos são muito importantes em razão da ampla diversidade linguística do Brasil.

Talvez o ideal fosse que junto ao nome popular de determinada espécie essas coleções trouxessem o seu nome científico, atrelando, dessa forma, o conhecimento do senso comum com o conhecimento científico (SALES; LANDIM, 2009). Todavia é necessário extremo cuidado com o uso da linguagem científica formal nos textos, principalmente nos livros de Ciências, para que não se tornem de difícil compreensão para os alunos do Ensino Fundamental. Dessa forma é possível conectar a linguagem científica com a linguagem do dia-a-dia do aluno e promover uma aprazível e melhor aprendizagem.

O A. fulica tem sido ampla e equivocadamente designado como "caramujo" que é nomenclatura própria para formas com hábitos aquáticos (RUPPERT et al., 2005). Segundo Brasil (2017) isso ocorre "provavelmente devido a uma 'cultura do caramujo' formada por longas campanhas educacionais e sanitárias visando o controle de espécies vetoras da esquistossomose".

O uso de imagens fotográficas é um recurso muito importante para o aprendizado. Elas auxiliam no processo de entendimento do conteúdo, enriquecendo o texto (BELMIRO, 2000), tornando a visualização da página do livro didático mais agradável. Para isso essas imagens devem ser claras precisas e de fácil compreensão, despertar a curiosidade e motivar o aluno.

Vasconcelos e Souto (2003) enfatizam que uma imagem adequada deve ser compreensível por si só, ter relação direta com o texto e, além de possuir legenda autoexplicativa, deve ser inserida à medida que a informação é apresentada, tomando-se o cuidado de não permitir que ela "confunda" o leitor, levando-o a uma interpretação errônea da realidade e, segundo Frison et al. (2009), é importante para os estudantes do ensino fundamental que o livro didático tenha imagens pois elas ajudam a entender melhor o conteúdo.

As imagens apresentadas nos livros analisados são coloridas o que contribui para a compreensão do texto, entretanto nem todas correspondem ao caracolgigante-africano e, ainda, algumas informações contidas nas legendas são incorretas. Segundo Ferreira e Selles (2003), os erros presentes nos livros didáticos dificultam o conhecimento dos alunos e a didática do professor, que, muitas vezes, acaba até mesmo sem perceber, transmitindo informações erradas.

Falhas dessa natureza comprometem o aprendizado do aluno que poderá criar um conceito errôneo, generalizado em relação às diferentes espécies, colocando em risco as populações de outros moluscos nativos como vem ocorrendo com o Megalobulimus paranaguensis (Figura 2), espécie da fauna silvestre ameaçada de extinção (BRASIL, 2014).

Moluscos do gênero Megalobulimus colocam apenas dois ovos a cada ciclo reprodutivo (THIENGO, 2007), enquanto o caracol-gigante-africano pode colocar até 442 ovos em uma única postura (FISCHER; COSTA, 2010). Essa característica torna o molusco nativo frágil quando confundido com o A. fulica. Segundo Pecora e Miranda (2014), o Megalobulimus paranaguensis está ameaçado de ${ }^{6}$ sobre-

\footnotetext{
${ }^{6}$ Sobre-explotação: Elevada condição de captura.
} 
explotação devido a degradação do seu ambiente natural e pela sobrematança causada por serem confundidos com o A. fulica.

Para a população, de forma geral, essa confusão é bastante comum tendo em vista as semelhanças em tamanho e horário de ${ }^{7}$ forrageamento, entretanto um olhar mais acurado mostrará nítidas diferenças no formato e coloração da concha - a concha do A. fulica tem mais giros e é mais alongada, já a do Megalobulimus $s p$ é mais bojuda, gorda, tem menos giros e sua abertura é espessa, não cortante (THIENGO, 2007), - na coloração corpórea e na morfologia entre essas duas espécies.

O histórico correto sobre a presença de espécies exóticas em diversos hábitats deve ser o mais completo possível para o entendimento dos motivos que levaram a essa introdução. Pereira et al. (2012) relatam que no ambiente antrópico, um fator que favorece a instalação do $A$. fulica é o acúmulo de lixo, local onde encontram abrigo e alimento farto.

Por ser o livro didático, muitas vezes, a única fonte de conhecimento de grande parte dos alunos, esses jovens levam essas informações como aprendizado para si e para seus familiares, de onde são difundidas para as comunidades onde vivem. Quando essas informações são desencontradas não propiciam ações apropriadas para solucionar os problemas causados ou amenizar suas consequências. Informações corretas ajudam a evitar novas introduções no ambiente de espécies exóticas muitas vezes beneficiadas pela degradação ambiental normalmente causada por ação antrópica.

A voracidade desse caracol tem causado prejuízos ambientais e econômicos por ser generalista em sua alimentação. $O$ hábito generalista associado à estratégia reprodutiva possibilita ao $A$. fulica a ocupação em ambientes antrópicos, como regiões peridomiciliares em áreas urbanas e em ambientes alterados pela agricultura (FISCHER; COSTA, 2010).

Os seis livros que fazem referência à voracidade dessa espécie não citam a sua presença nos ambientes antropizados - praças públicas, quintais e terrenos baldios. Nestes, quando malcuidados, o A. fulica encontra uma gama de diferentes materiais que lhe serve de abrigo e alimento com farta disposição de cálcio (retirado de entulhos) usado na confecção da concha. Em quintais atacam jardins, plantas ornamentais e hortas onde, além do prejuízo, deixam o muco que pode estar contaminado com larvas infectantes do A. cantonensis ou do A. abstrusus causador de pneumonia em gatos.

As informações sobre a taxa de reprodução são reportadas em cinco livros. No livro 7 consta que "os indivíduos são hermafroditas e produzem milhares de ovos por ano". Essa informação é correta, porém a superpopulação não foi relacionada à ausência de predadores e à estratégia reprodutiva.

Embora a oviposição somente se inicia quando o molusco encontra condições favoráveis, como terra fofa e umidade (FISCHER; COSTA, 2010), cada indivíduo pode colocar em média 200 ovos por postura e se reproduzir mais de uma vez por ano; seus ovos - que tem mais ou menos do tamanho de uma semente de mamão, branco-amarelados (Figuras 6 à direta) - são depositados em covas feitas no solo.

\footnotetext{
${ }^{7}$ Forrageamento: busca e exploração de recursos alimentares.
} 
A presença dessas informações no texto acompanhadas de imagens corretas dos ovos auxiliará o entendimento e a identificação em ações de manejo.

Moluscos dessa espécie podem transmitir parasitos para os seres humanos por serem hospedeiros intermediários de nematódeos como o A. cantonensis agente etiológico da meningoencefalite eosinofílica.

Guerino et al. (2017) relataram a presença de Achatina fulica infectada por A. cantonensis em todos os nove municípios que compõem a região metropolitana da Baixada Santista no litoral do estado de São Paulo, Brasil. Segundo kliks e Palumbo (1992), a expansão mundial desse parasito está ligada à dispersão e colonização pelo caracol-gigante-africano

Essas informações são importantes para os alunos e seus familiares uma vez que as pesquisas mais recentes vêm demonstrando que, cada vez mais, esses moluscos são encontrados infectados com nematoides.

As medidas de controle sobre populações exóticas são muito importantes para a preservação do ambiente e da biodiversidade, além de evitar prejuízos econômicos e proliferação de doenças relacionadas ao invasor. Essas medidas só foram citadas em três livros e estão de acordo com as informações da maioria dos pesquisadores e dos órgãos públicos competentes, porém estão incompletas.

Sem os conhecimentos adequados muitos moradores das áreas invadidas têm o hábito de jogar sal nos moluscos, o que não é recomendado pois, além de ser ineficiente pode causar a salinização do solo e impactos aos microrganismos e invertebrados que ali vivem, prejudicado o solo e plantio (PAIVA, 2004).

O Plano de Ação para o Controle do A. fulica do Instituto Brasileiro do Meio Ambiente e dos Recursos Naturais Renováveis (IBAMA) recomenda a catação manual com uso de luvas seguido de esmagamento, sendo os restos enterrados e cobertos com cal virgem. Segundo Thiengo (2007), em entrevista à agência Fiocruz, outras opções para o controle desse molusco são jogar água fervente no recipiente onde estão recolhidos para matá-los ou ainda, incinerá-los devendo os restos serem ensacados e descartados em lixo comum tomando-se o cuidado de quebrar as conchas para que não acumulem água e se transformem em criadouros de mosquitos como o Aedes aegypti.

\section{CONCLUSÕES}

A ausência total de qualquer menção ao caracol-gigante-africano $A$. fulica em algumas coleções didáticas pode levar os alunos das escolas que adotaram tais coleções a não ter a oportunidade de adquirir conhecimentos sobre como lidar com esses invasores que vão, possivelmente, encontrar em seu caminho para a escola ou até mesmo dentro delas, onde, às vezes, os usam para brincadeiras sem os necessários cuidados no manejo e sem o respeito devido aos seres vivos, sejam eles quais forem.

O A. fulica é uma espécie invasora presente em todo o território nacional e um dos principais responsáveis pela introdução do $A$. cantonensis no continente sul-americano, tornando a meningite eosinofílica uma infeç̧ão de importância em saúde pública no Brasil. 
Pouca disponibilidade de informações e esclarecimentos quanto ao manejo, faz com que o $A$. fulica seja frequentemente confundido com os moluscos nativos do gênero Megalobulimus. Como o molusco nativo do Brasil se reproduz de forma mais lenta, é importante poder distinguir as diferenças entre os dois para que a espécie brasileira não seja prejudicada. Sua eliminação certamente implicaria em desequilíbrio ecológico na malacofauna brasileira.

As omissões/incorreções em conceitos e imagens, além de legendas incorretas em algumas imagens disponibilizadas podem comprometer o aprendizado e dificultar a compreensão das causas das doenças por parte dos alunos, inviabilizando possíveis atividades práticas voltadas à prevenção da saúde e do ambiente e ao controle da população invasora.

Como os autores dos livros didáticos não podem tratar de todos os aspectos relacionados às doenças e suas causas e aos problemas de meio ambiente de forma igual e menos ainda de uma forma completa - para que o LD não se torne uma enciclopédia - e ainda, aos tratá-los, devem levar em conta o público a atingir (EF II ou EM) torna-se necessário que o professor se mantenha constantemente atualizado, na tentativa de encontrar uma forma de minimizar os problemas decorrentes da falta de acesso às informações em sua tarefa de instruir o aluno.

Muitas vezes esse professor não tem acesso a fontes atualizadas, pois há escolas que ainda não contam com acesso fácil às informações sugeridas pelos Parâmetros Curriculares Nacionais como jornais, revistas, computadores e filmes, outras que não possuem meios eletrônicos facilitadores da informação como a internet e outras que ainda não possuem energia elétrica.

Levando-se em conta as dificuldades encontradas pelos professores nas diversas regiões do Brasil, seria bem-vindo um critério diferenciado por parte dos autores das coleções didáticas ao tratar de temas novos e de interesse em nível de saúde pública e meio ambiente, pois a informação correta e completa contribui na construção do conhecimento e na formação de atitudes que minimizam o risco de se contrair doenças. 


\title{
The African giant snail Achatina fulica (Bowdich, 1822): analysis of contents in science and biology textbooks indicated by the 2017 / 2018 national program of didactic nook (PNLD)
}

\begin{abstract}
The presence of contents on the African giant snail Achatina fulica in the Sciences and Biology collections indicated by the 2017/2018 PNLD was verified, as well as the presence of images and information regarding the transmission of diseases and alerts on the management and control of the population of this exotic invasive species. The results revealed the absence of any mention of the snail in $50 \%$ of Sciences collections and in $30 \%$ of Biology collections, and omissions / inaccuracies in concepts and images, and some misplaced legends in the contents were found. It was concluded that there is need for greater care in the elaboration of these collections when dealing with topics of interest to public health and environment, because correct information contributes to the construction of knowledge and the formation of attitudes that minimize the risk of contracting diseases and avoid the frequent confusion between Achatina fulica and Megalobulimus sp threatened of extinction.
\end{abstract}

KEYWORDS: African snail. Invasive snail. Public health. Environment. 


\section{REFERÊNCIAS}

Belmiro, C. A. A imagem e suas formas de visualidade nos livros didáticos de Português. Educação \& Sociedade, v.21, n.72, p. 11-31, 2000.

Brasil, 1998. Secretaria de Educação Fundamental. Parâmetros curriculares nacionais: Ciências Naturais. Brasília: MEC/SEF, 1998.

Brasil, 2014. Diário Oficial do Estado de São Paulo. Decreto № 60133 de 07/02/2014 - Declara as espécies da fauna silvestre ameaçadas de extinção, as quase ameaçadas e as deficientes de dados para avaliação no Estado de São Paulo e dá providências correlatas. Publicado no DOE em 8 fev. 2014. Disponível em: https://www.al.sp.gov.br/repositorio/legislacao/decreto/2014/decreto60133-07.02.2014.html. Acesso em: 03 mar. 2018.

Castro, F. Caramujo invasor. Agência FAPESP, 2006. Disponível em: http://agencia.fapesp.br/caramujo_invasor/6491/. Acesso em: 03 dez. 2017.

Ferreira, M. S.; Selles, S.E. A produção acadêmica brasileira sobre livros didáticos em ciências: uma análise em periódicos nacionais. IV Encontro Nacional de Pesquisa em Educação em Ciências; 2003. Bauru, SP, Brasil. Disponível em: http://fep.if.usp.br/ profis/arquivos/ivenpec/Arquivos/Orais/ORAL020.pdf. Acesso em: 15 dez. 2017

Fischer, M. L.; Colley, E. Espécie invasora em reservas naturais: caracterização da população de Achatina Fulica Bowdich, 1822 (Mollusca - Achatinidae) na Ilha Rasa, Guaraqueçaba, Paraná, Brasil. Biota Neotropica, v.5, n..1, 2005. Disponível em http://www.scielo.br/scielo.php?script=sci_arttext\&pid=S1676-

06032005000100014. Acesso em 30 abr. 2018.

Fischer, M. L.; Costa, L. C. M. O caramujo gigante africano Achatina fulica no Brasil. 1a ed. Curitiba: Champagnat. 2010.

Frison, M. D.; Vianna, J.; Chaves, J. M.; Bernardi, F. N. Livro Didático como Instrumento de Apoio para Construção de Propostas de Ensino de Ciências Naturais. VII Encontro Nacional de Pesquisa em Educação em Ciências; 2009. Florianópolis, SC, Brasil. Disponível em: http://posgrad.fae.ufmg.br/posgrad/viienpec/pdfs/425.pdf. Acesso em: 16 dez. 2017.

Guerino, L. R.; Pecora, I. L.; Miranda, M.S.; Aguiar-Silva, C.; Carvalho, O. S.; Caldeira, R. L.; Silva, R. J. Prevalence and distribution of Angiostrongylus 
cantonensis (Nematoda, Angiostrongylidae) in Achatina fulica (Mollusca, Gastropoda) in Baixada Santista, São Paulo, Brazil. Revista da Sociedade Brasileira de Medicina Tropical, v. 50, n. 1, p. 92-98, 2017.

Kliks, M. M.; Palumbo, N. E. Eosinophilic meningitis beyond the Pacific Basin: The global dispersal of a peridomestic zoonosis caused by Angiostrongylus cantonensis, the nematode lungworm of rats. Social Science \& Medicine, v. 34, n. 2. p. 199-212, 1992.

Lajolo, M. Livro Didático: um (quase) manual de usuário. Revista Em Aberto, v. 69, p. 3-9, 1996. Disponível em http://www.dominiopublico.gov.br/download/texto/me001398.pdf. Acesso em: 22 jan. 2018.

Lowe, S.; Browne, M.; Boudjelas, S.; De Poorter, M. 100 of the world's worst invasive alien species a selection from the global invasive species database. Published by The Invasive Species Specialist Group (ISSG) a specialist group of the Species Survival Commission (SSC) of the World Conservation Union (IUCN), 2004. Disponível em https://testportals.iucn.org/library/sites/library/files/documents/2000-126.pdf. Acesso em: 29 dez. 2017.

Menezes, M. Casos de meningite transmitida por caramujo se espalham pelo país. Portal Fiocruz. 2014. Disponível em https://portal.fiocruz.br/pt$\mathrm{br} /$ content/meningite-transmitida-por-caramujos-com-avanco-de-casoscientistas-alertam-para-prevencao. Acesso em: 22 mar. 2018.

Morassutti, A. L.; Graeff-Teixeira, C.; Rodrigues, R.; Agostini, A.; Rebello, K. M. Angiostrongilíases: da biologia ao enfoque clínico. Dados eletrônicos. Porto Alegre: EDIPUCRS, 2014.

Murta, F. L. G.; Modena, C. M.; Carvalho, O. S.; Massara, C. L. Abordagem sobre esquistossomose em livros de ciências e biologia indicados pelo Programa Nacional do Livro Didático (PNLD) - 2011/2012. Revista de Patologia Tropical, v. 43, n. 2, p. 195-208, 2014.

Oliveira, J. C. S.; Corrêa, K. J. G.; Vasconcelos, H. C. G. Ocorrência de Achatina fulica (Mollusca: Pulmonata: Achatinidae) em três bairros da cidade de Santana, Amapá. Biota Amazônica, v. 3, n. 1, p. 9-12, 2013. 
Paiva, C. L. Achatina fulica (Moluscos): praga agrícola e ameaça à Saúde Pública no Brasil. 2004. Disponível em: httpp://www.geocites.ws/lagopaiva/achat_tr. htm. Acesso em: 20 fev. 2018.

Pecora, I.L.; Miranda, M. S. Salvando e aprendendo com Megalobulimus. Revista Ciência em Extensão, v.10, n. 1, p. 72-82, 2014.

Pereira, Z. M.; Thiengo, S. C.; Monteiro, S. O caramujo africano em contexto escolar: as percepções de estudantes do ensino fundamental e o estudo da helmintofauna associada ao caramujo em Barra do Piraí (RJ). Revista Ensaio Pesquisa em Educação em Ciências, v. 14, n. 3, p. 275-288, 2012. Disponível em: http://www.scielo.br/pdf/epec/v14n3/1983-2117-epec-14-03-00275.pdf. Acesso em: 22 mar. 2018.

Rupert, E. E.; Fox, R. S.; Barnes, R. R. Zoologia dos invertebrados: uma abordagem funcional/evolutiva. 7̣a ed. Roca, São Paulo, 2005.

Sales, A. B.; Landim, M. F. Análise da abordagem da flora nativa em livros didáticos de Biologia usados em escolas de Aracaju - SE. Experiências em Ensino de Ciências, v 4, n 3, p. 17-29, 2009.

Santos, J. C.; Alves, L. F. A.; Corrêa, J. J.; Silva, E. R. L. Análise comparativa do conteúdo filo Mollusca em livro didático e apostilas do ensino médio de Cascavel, Paraná. Ciência \& Educação, v. 13, n. 3, p. 311-322, 2007.

Telles, H. M. S.; Vaz, J. F.; Fontes, L. R.; Domingos, M. F. Ocurrence of Achatina fulica Bowdich, 1822 (Mollusca, Gastropoda) in Brazil: intermediate snail host of Angiostrongyliasis. Revista de Saúde Pública, v. 31, n. 3, p. 10-12, 1997.

Thiengo, S. C. Especialista comenta os riscos que os caramujos africanos podem representar para a população. Agência FIOCRUZ de Notícias - Saúde e Ciência para todos, 2007. Disponível em: https://agencia.fiocruz.br/especialistacomenta-os-riscos-que-os-caramujos-africanos-podem-representar-para-apopula\%C3\%A7\%C3\%A3o. Acesso em: 25 jan. 2018.

Tsai, H. C.; Liu, Y. C.; Kunin, C. M.; Lee, S. S.; Chen, Y.; Lin, H.; Tsai, T.; Lin, W.; Huang, C.; Yen, M.; Yen, C. Eosinophilic meningitis caused by Angiostrongylus cantonensis: report of 17 cases. The American Journal of Medicine, v. 111, n. 2, p. 109-114, 2001. 
Vasconcelos, M. C.; Pile, E. Ocorrência de Achatina fulica no Vale do Paraíba, Estado do Rio de Janeiro, Brasil. Revista de Saúde Pública, v. 35, n. 6, p. 582-584, 2001.

Vasconcelos, S.D.; Souto, E. O livro didático de ciências no ensino fundamental proposta de critérios para análise do conteúdo zoológico. Ciência \& Educação, v. 9, n. 1, p. 93-104, 2003.

Verceze, R. M. A. N.; Silvino, E. F. M. O livro didático e suas implicações na prática do professor nas escolas públicas de Guajará-Mirim. Práxis Educacional, v. 4, n. 4, p. 83-102, 2008.

Wen YF. Development of Angiostrongylus cantonensis in the lung of Achatina fulica. Chinese Journal of Microbiology, v. 10, n. 3, p 74-79, 1977. Disponível em: http://europepmc.org/abstract/med/580235. Acesso em: 05 jan. 2018.
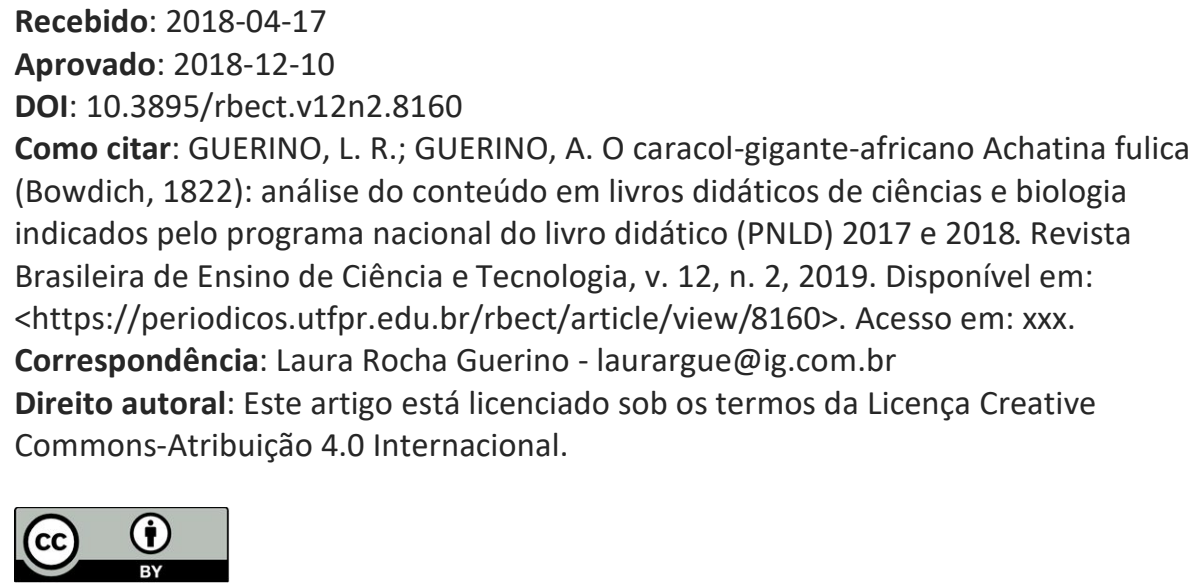